\title{
214 Book Reviews
}

and maps, were not to serve as daily-use objects for the deceased in his or her "happy home" in the tomb, but were objects to be used for travel outside the tomb, in a journey of the soul to a cosmic destination in the far northwest. He further argues that this western/northwestern destination laid the groundwork for the later cult of the Queen Mother of the West (Xiwangmu) and the Buddhist pure lands, which would also focus on western paradises for the dead. While the theory about some objects in the tomb serving as travel paraphernalia is fairly well demonstrated, since funerary-object lists from sites like Baoshan identify them as "paraphernalia used for travel," the hypothesis about the northwestern destination for a postmortem journey is a little less grounded. Much of this argument rests on a single incantation from Jiudian tomb no. 56, which mentions the mythical "wilds of Buzhou" in the far northwest as a destination for those who died by weapons. Lai suggests that the war dead were compelled through rituals to travel to this far-off place to control their dangerous spirits, building on his argument in chapter one. However, Lai appears to extend this one piece of evidence to suggest that the souls of all the dead traveled to this same place $(161,165)$. Still, it is a stimulating theory which requires serious consideration and should be reexamined in the light of future excavations.

Urbanization in Early and Medieval China: Gazetteers for the City of Suzhou. By Olivia MilbuRn. Seattle: University of Washington Press, $2015 . x x+360$ pp. $\$ 50$ (cloth).

\section{Reviewed by Cong ElLen Zhang, University of Virginia (cz5h@virginia.edu)} doi:10.1017/jch.2016.16

Best known for its natural beauty, elaborate gardens, and thriving artistic and literary communities in the late imperial period, Suzhou also occupies an important place in the history of urban planning. Built in 514 B.C. by King Helü (r. 514-496 BCE) as the capital city of the state of Wu, it is one of the world's oldest recorded planned cities. Geographic and local history writing about Suzhou is voluminous, making it the Chinese city about which we know the most. Based on the three earliest gazetteers about Suzhou and its surrounding area, Olivia Milburn's important work adds many rich layers to our knowledge of the city's history from its founding to the end of the Northern Song.

At the heart of Urbanization in Early and Medieval China are complete translations of Tales of the Lands of Wu (Ji Wudi zhuan 記吳地傳, hereafter Tales), compiled in the early Eastern Han, Record of the Lands of Wu (Wudi ji 吳地記, hereafter Record) by Lu Guangwei (n.d.) in the Tang, and Supplementary Records to the "Illustrated Guide to Wu Commandery" (Wujun tujing xuji 吳郡圖經續記, hereafter Supplementary Records) by Zhu Changwen (1039-98) of the Northern Song. Written over a period of a thousand years, these texts were composed at important points in history and are rare survivals from the early and mid-imperial times. The Lost Histories of Yue (Yuejue shu 越絶書), of which the Tales was a part, is conventionally considered the first gazetteer ever to have been written in China. The Record is one of only six surviving Tang dynasty gazetteers, completed in 876 , a year before Suzhou was sacked by a regional rebellion. The Supplementary Records, one of two surviving Northern Song gazetteers, was composed in 1084 and meant to complement Li Zong'e's (964-1012) long-lost Illustrated Guide to Suzhou (Suzhou tujing 蘇州圖 經). Zhu Changwen's detailed accounts of Suzhou's infrastructure and architecture are of special historical importance. Since the city suffered tremendous damage in the Jurchen invasion of 1130, Supplementary Records preserved valuable information about Suzhou's cultural and historical landscape that was crucial to local residents, visitors, and gazetteer writers in later times. 
Milburn is the first to make these earliest gazetteers available in accessible English. As we might expect of historical geographic literature, the texts contain a great variety of unique information, including descriptions of and allusions to important events in local history, prominent personalities, a large number of government agencies, and abundant natural and historical landmarks such as mountains and lakes, walls and gates, roads and canals, and palaces and commemorative structures. The texts also vary in style and structure. Each of Milburn's translations remains faithful to the sense of the originals. She has also carefully supported her translations with hundreds of wellresearched and helpful notes, an excellent index and glossary, and multiple, useful tables, maps, and illustrations.

As much as each translation is an enjoyable read, the book is more than a translation volume. Its introduction gives a thorough overview of Suzhou's political, administrative, and social and cultural history that traces, among other things, its evolution from the capital of the state of Wu to a minor provincial city in early imperial times, its emergence as a major Buddhist center during the Period of Disunity, and the formation of the city's local, cultural, and ethnic identity from the late Spring and Autumn Period to the Northern Song. The book's Commentary chapter discusses Suzhou's place in the history of urban planning, a question that has attracted much scholarly attention in recent decades. Milburn argues that scholars in China, by viewing Suzhou as a "typical" Chinese city, constructed according to the ideal city plan found in the "Record of Artificers" (Kaogong ji 考工記) chapter of the Rites of Zhou (Zhouli 周禮), “have ignored the issue of the ethnicity of the original inhabitants of the city." Using recent archeological findings and other textual evidence, she concludes that, "Although there is some evidence of an association between this classic form of urban design and the plan actually imposed on Suzhou, there is equal evidence that the ancient city was very different from contemporary cities in the Zhou confederacy and subject to planning principles that were probably derived from Bai Yue culture" (209). Given that surviving sources, including the three gazetteers, tell us very little about what the city actually looked like, Milburn is careful to add that "the theory that the original design of this city was influenced by traditional Bai Yue urban planning is also problematic" (250).

Another focus of the Commentary chapter is on the development of geographic writing as a genre of literature. Through a comparison of the ways natural landscape, ancient sites, temples, crime and punishment, and war and natural disasters were represented in the three texts, Milburn is able to identify important conventions as well as noteworthy changes in gazetteer writing. She especially singles out Zhu Changwen's role in "improving the quality of gazetteer writing in Suzhou," highlighting the comprehensiveness of Zhu's work and the great trouble he went to in assuring the accuracy of his compilation. I wonder, given that we know so little about the authors/compilers of the two earlier gazetteers, why Zhu's preface, which touched on the history of gazetteer writing and his commitment to and vision for the project, is not included in the translation. Additionally, at least four postfaces (dated to 1086, 1092, 1096, and 1134) to Zhu's work were composed in the Song. Milburn briefly refers to them, but a full translation and comprehensive analysis of these texts would have deepened our understanding of evolving ideas on gazetteer and local history writing at a crucial moment in Chinese history and the place of Supplementary Records in shaping the history of Suzhou.

Milburn's work is a very welcome addition to the literature on Suzhou, urban planning in Chinese and world history, and the development of China's historical and cultural landscape. The rich materials contained in the gazetteers will be of interest to specialists as well as graduate and undergraduate students. 